\title{
Physical and Mental Health Status and Its Related Demographic Factors in Martyr's Elderly Parents: A Case Study of Tehran City
}

\section{ART ICLE INF O}

\section{Article Type}

Descriptive Study

\section{Authors}

Hosseini R.S. ${ }^{1} M S C$

Abolfathi Momtaz Y.*1 $P h D$,

Mohammadi Shabalaghi F. ${ }^{1} P h D$,

Soroush M.R. ${ }^{2} M D$

$\mathrm{MPH}$, Delbari A. ${ }^{1} \mathrm{PhD}$

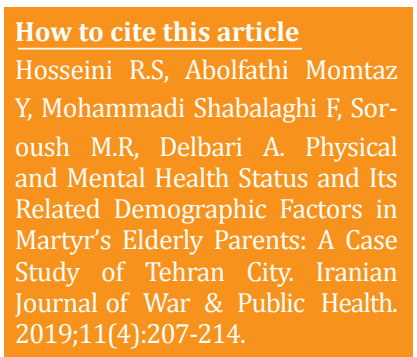

${ }^{1}$ Iranian Research Center on Aging, University of Social Welfare \& Rehabilitation Sciences, Tehran, Iran ${ }^{2}$ Janbazan Medical and Engineering Research Center (JMERC), Tehran, Iran

\section{*Correspondence}

Address: Iranian Research Center on Aging, University of Social Welfare and Rehabilitation Sciences, Koodakyar Street, Daneshjoo Boulevard, Velenjak Square, Tehran, Iran. Postal Code: 1985713834

Phone: +98 (21) 22180154

Fax: -

yabolfathi@gmail.com

\section{Article History}

Received: April 28, 2019

Accepted: July 10, 2019

ePublished: December 21, 2019

\section{A B S T R A C T}

Aims Health is one of the fundamental rights of every human as well as it is a social aim and all governments are responsible for people's health. This study aimed to investigate the physical and mental health and its related demographic factors in martyr's elderly parents. Instruments \& Methods This cross-sectional descriptive study was carried out on martyr's elderly parents in Tehran, Iran in 2018. 600 individuals were selected by proportionate random sampling method. Data collection was conducted using a demographic questionnaire, the activities of daily living (ADL) questionnaire and world health organization (five) wellbeing index (WHO-5). Data were analyzed by SPSS 23 software through independent t-test, one-way analysis of variance and Tukey's post-hoc test.

Findings The mean scores obtained for the activities of daily living was $10.07 \pm 3.17$ and the mean scores obtained for world health organization (five) well-being index was $11.60 \pm 5.87$. There was a significant relationship between the ability to doing activities of daily living and mental well-being with demographic characteristics including age, gender, marital status, ability to read and write and the number of income sources $(\mathrm{p}<0.05)$.

Conclusion Physical and mental health status of martyr's elderly parents in Tehran city is in the low level and it has a relationship with demographic characteristics including age, gender, marital status, ability to read and write and the number of income sources.

Keywords Physical Fitness; Mental health; Activity of Daily Living; Well-being; Parents; Elderly; Martyr

\section{I T A T I O N L I N K S}

[1] General health and its related factors among elderly in Sabzevar ... [2] Health physical and mental status in the elderly of ... [3] Relationship between oral health and ... [4] Life satisfaction in older adults: role of perceived ... [5] A review of the Iran's elderly status according to the ... [6] The relationship between social interest and general health ... [7] Biological psychological and social determinants of old age ... [8] Factors related to healthrelated quality of life ... [9] Successful ageing in an area of deprivation ... [10] A review on adult daycare Centers in the ... [11] A Content analysis of the concepts and images of the ... [12] The impact of quality of life on the health of older ... [13] An investigation Iraq's strategies against Islamic ... [14] Mental health consequences of war: a brief review ... [15] Personal well-being and stress symptoms in wives of Iranian ... [16] The effect of imposed war on Iran's nursing: a historical ... [17] A study on depression among war martyrs' widows ... [18] Physical health status and socio-economic outcomes on elderly ... [19] Studies of illness in the ... [20] Psychometric properties of the Persian version of ... [21] The WHO-5 well-being index: a systematic review of ... [22] An investigation into psychometric properties ... [23] Assessment of health status of elderly people in the ... [24] Determining the status of activity of daily living ... [25] Comparative study of physical and mental health status of old people in aged ... [26] Validation of the Persian of abbreviated mental test (AMT) in ... [27] Quality of life and status of physical functioning among ... [28] Activities of daily living and prevalence of ... [29] Quality of life in Zahedan elderly ... [30] Factors associated with basic and instrumental ... [31] Assessment of psychosomatic health status in ... [32] Measuring national well-being- health ... [33] Measuring mental health of the Dutch population ... [34] Comparing the effects of group and home-based ... [35] Mental health status and related factors in aged ... [36] Mental health and related factors in old population in ... [37] Mental health survey of the adult population ... 
اغلب جوامع، سالمندان با بيشترين خطر كاهش توانايىهاى

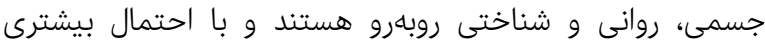

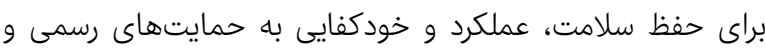

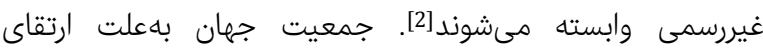

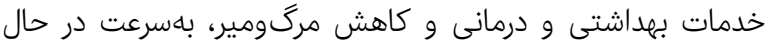

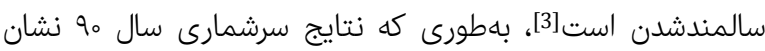

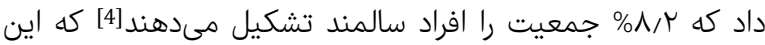

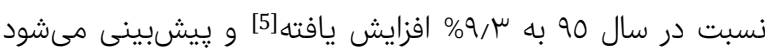

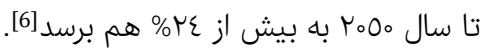
فرآيند سالمندى مىتواند به اضمحلال ذهنى، جسمى و إنى كاهش سالهاى فعال مورد انتظار و سالم منجر شود. تغييرات وضعيت إندات

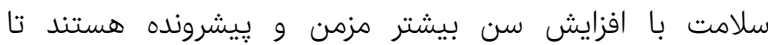

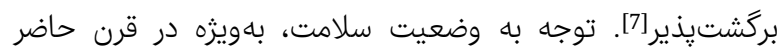

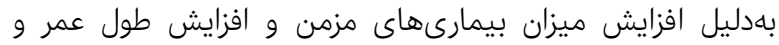

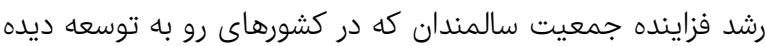

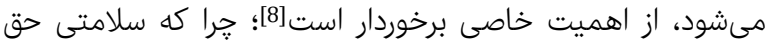

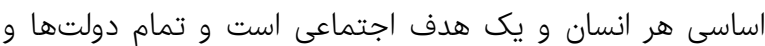

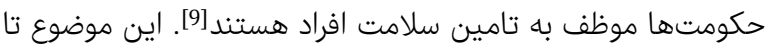

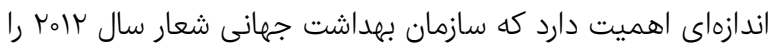

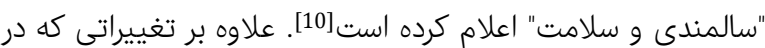

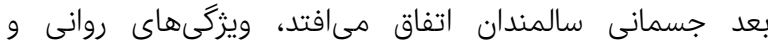

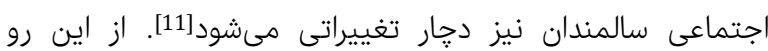
علىرغم ارايه مفاهيم نوينى از قبيل كيفيت زندكى نئ، مفهوم و

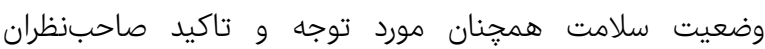
است]

از سوى ديكر، بر طبق نظريه دوره زندگى، برخى حوادث كه در طول

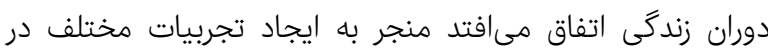

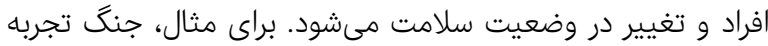

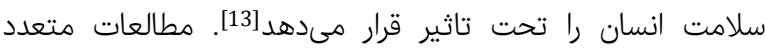

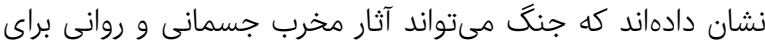

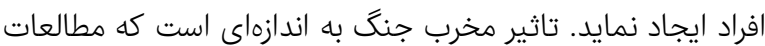

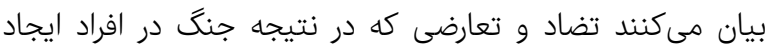

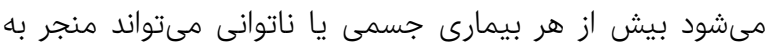

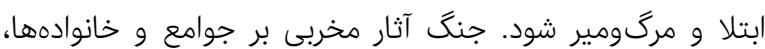

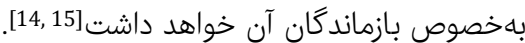

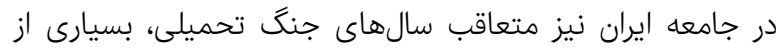

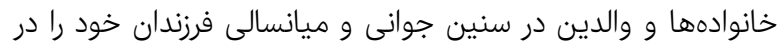

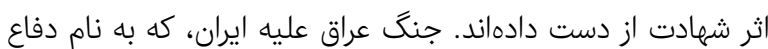

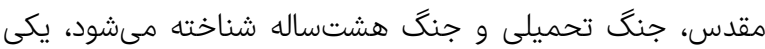

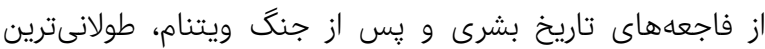

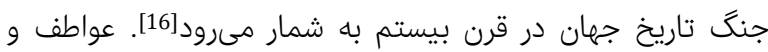

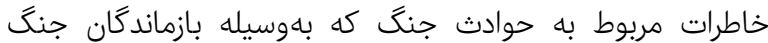

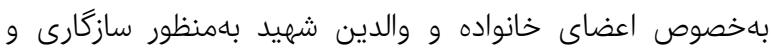
برآوردن ضروريات زندگى طبيعى سركوب مىشوند، در دورهاى از
وضعيت سلامت جسمانى و روانى روانى و عوامل جمعيتشناختى مرتبط با آن در والدين سالمند شهدا؛ مطالعه موردى شهر تهران

راضيه السادات حسينى MSc مركز تحقيقات سالمندى، دانشكاه علوم بهزيستى و توانبخشى، تهران، ايران

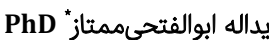
مركز تحقيقات سالمندى، دانشكاه علوم بهزيستى و توانبخشى، تهران، ايران

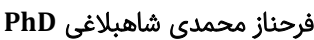
مركز تحقيقات سالمندى، دانشكاه علوم بهزيستى و توانبخشى، تهران، ايران

Mحمدرضا سروش مدركز تحفيقات مركز تحقيقات مهندسى و علوم يزشكى جانبازان، تهران، ايران PhD احمد دلبرى تحنيفات مركز تحقيقات سالمندى، دانشكاه علوم بهزيستى و توانبخشى، تهران، ايران

جكيده اهداف: سلامتى حق اساسى هر انسان و يك هدف اجتماعى است و تمام دولتها و حكومتها موظف به تامين سلامت افراد هستند. اين مطالعه با هدف بررسى وضعيت سلامت جسمانى و روانى و عوامل جمعيتشناختى مرتبط با آن در والدين سالمند شهدا انجام كرفت.

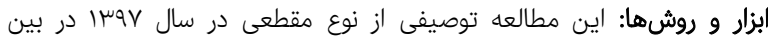

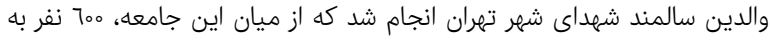

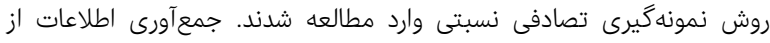

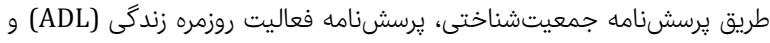

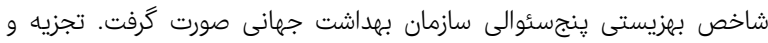

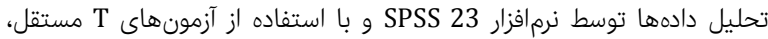
آناليز واريانس يكنطرفه و آزمون تعقيبى توكى انجام شدار

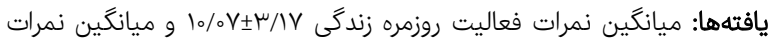

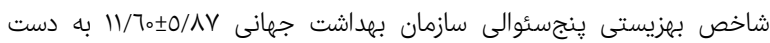

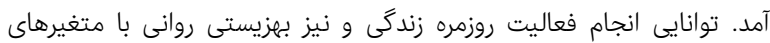

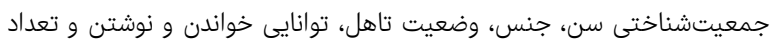

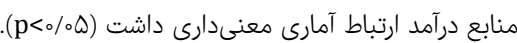

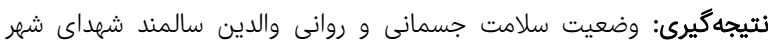
تهران در سطح يايين است و با عوامل جمعيتشناختى نظير سن، جنسيت،

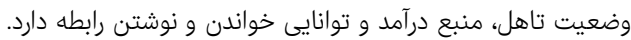

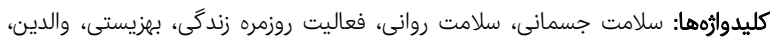
سالمند، شهدا

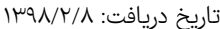

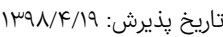

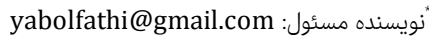

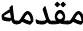

سلامتى داراى ابعاد جسمى، روانى و اجتماعى است كه شرط لازم و ضرورى براى ايفاى نقشهاى فردى و اجتماعى بوده و همه إنى انسانها در صورتى مىتوانند فعاليت كامل داشته باشند كهای هـ هم خود را سالم احساس كنند و هم جامعه آنها را سالم بداند[1]. در 
وضعيت سلامت جسمانى و روانى و عوامل جمعيتشناختى مرتبط با آن در والدين سالمند شهدا...

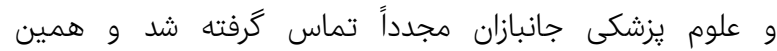

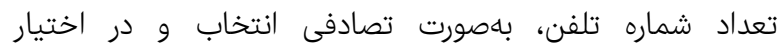
زندگى بهويزه با بالارفتن سن دوباره ظاهر شده و موجب بروز يزگوهشگر قرار كرفت.

روش كار به اين صورت بود كه در ابتدا، طى تماس تلفنى بار بال

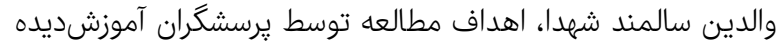

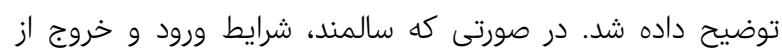

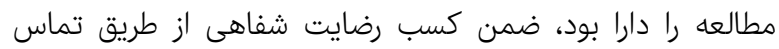

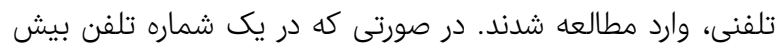

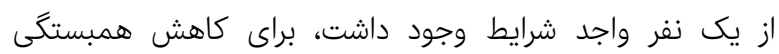

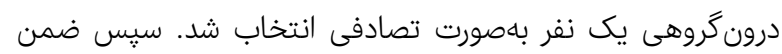

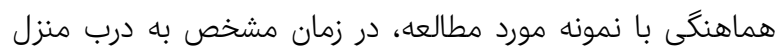
آنها مراجعه و يرسشنامهنها در محل و باهصورت مصاحبه تكميل

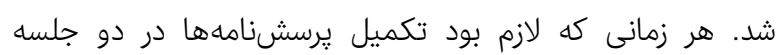
صورت كرفت.

براى جمعآورى اطلاعات از يرسشنامههاى زير استفاده شد:

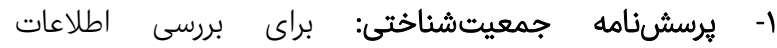

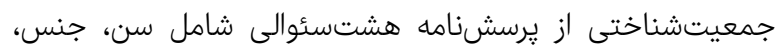

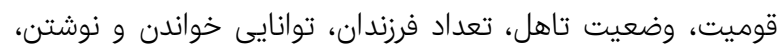

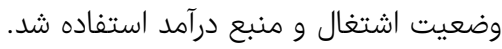
ץ- برسشنامه فعاليت روزمره زندگى (ADL): براى بررسى سلامت

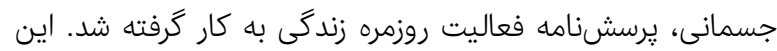

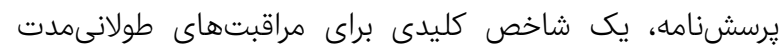

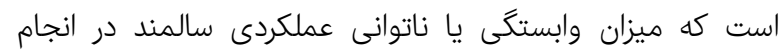

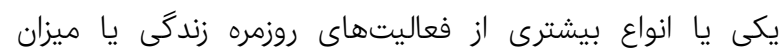

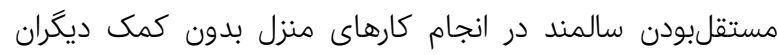

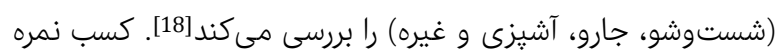

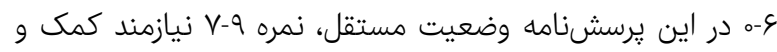

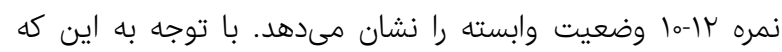

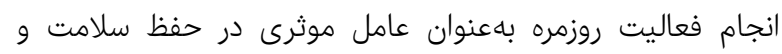

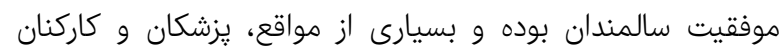

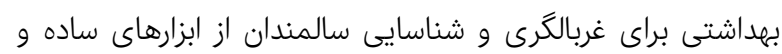

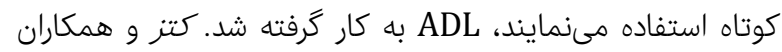

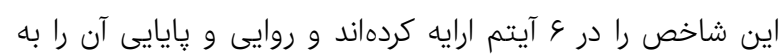

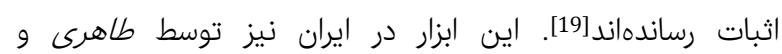

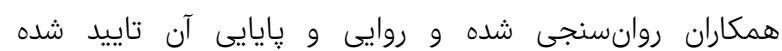
است [20].

س- شاخص بهزيستى ينجسئوالى سازمان بهداشت جهانى WHO-5 Well-Being Index)

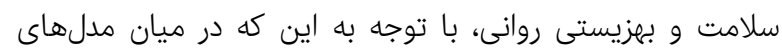

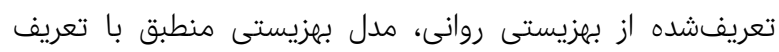

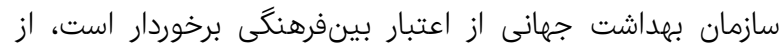

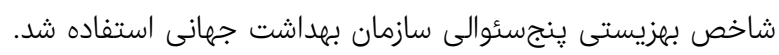

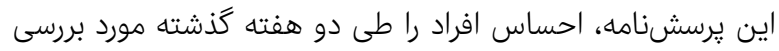

علايم جسمانى و روانى مى شود [17].

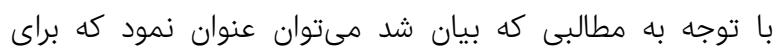

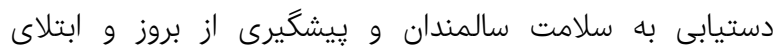

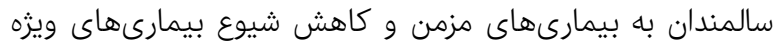

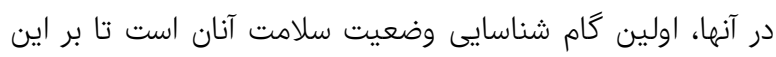

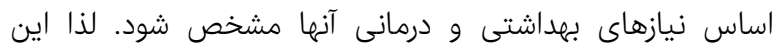
مطالعه با هدف بررسى وضعيت سلامت جسمانى و روانى و و روانى عوامل جمعيتشناختى مرتبط با آن در والدين سالمند شهدا انجام كرفت.

\section{ابزار و روشها}

اين مطالعه توصيفى از نوع مقطعى در سال وسرا در بين والدين

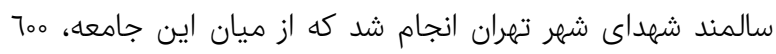
نفر به روش نمونهگيرى تصادفى نسبتى وارد مطالعه شدند. معيار

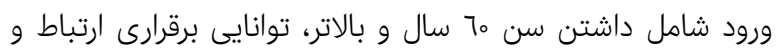

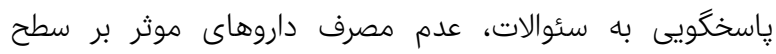

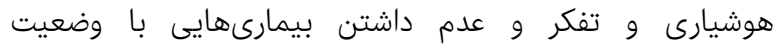

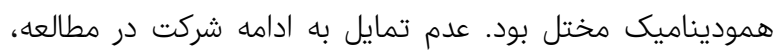
تكميل ناقص يرسشنامه و شرايط حاد جسمانى يا روانى در طول

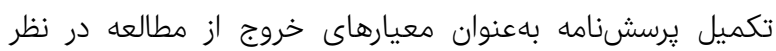

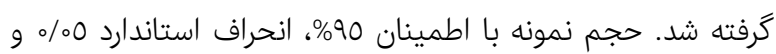

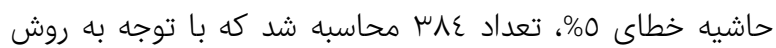
نمونه

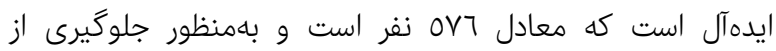

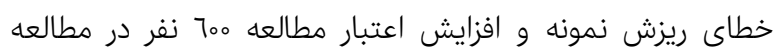
شركت داده شدند. يس از تصويب طرح در كميته اخلاق دانشگاه علوم بهزيستى و دهن

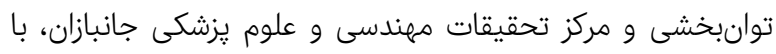

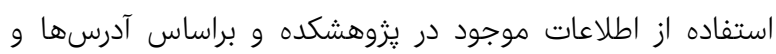

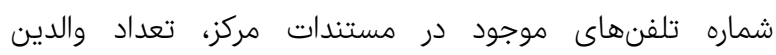

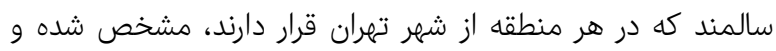

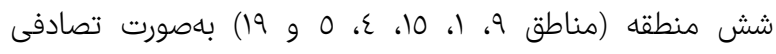
انتخاب شد. در هر يك از مناطق انتخابشده با توجه به فراوانى أه

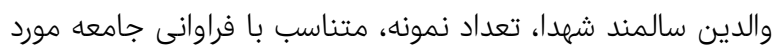

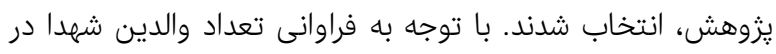

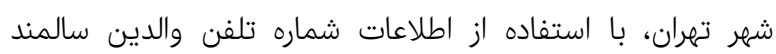

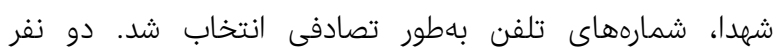

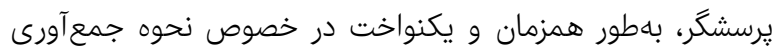

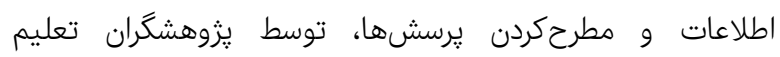

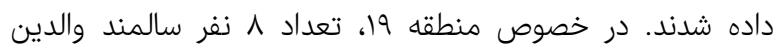

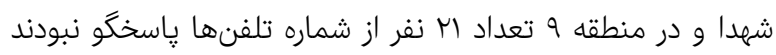

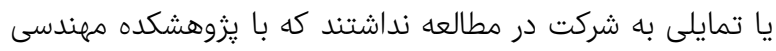




\begin{tabular}{|c|c|c|}
\hline \multicolumn{3}{|c|}{ جدول () توزيع فراوانى مطلق و نسبى متغيرهاى دموگرافيك والدين سالمند } \\
\hline \multirow[t]{2}{*}{ درصد } & تعداد & متغيرهاى دموگرافيك \\
\hline & & سن (سال) \\
\hline$\mu \vee / 0$ & rro & $T_{0}-V_{\varepsilon}$ \\
\hline$\varepsilon V / r$ & rАн & $\vee 0-\wedge \varepsilon$ \\
\hline \multirow[t]{2}{*}{$10 / \mu$} & 94 & بالاى 10 \\
\hline & & جنس \\
\hline$\mu\urcorner / \mu$ & MIA & مرد \\
\hline \multirow[t]{2}{*}{$7 \mu / \mathrm{V}$} & rAr & 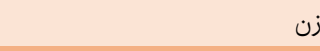 \\
\hline & & 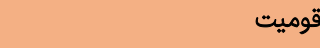 \\
\hline$O V / \Lambda$ & $\mu \varepsilon \mu$ & فارس \\
\hline$\mu \vee / \Lambda$ & rrr & 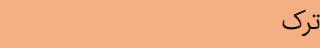 \\
\hline$r / 0$ & 10 & 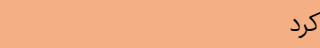 \\
\hline$r / \Lambda$ & IV & ر \\
\hline \multirow[t]{2}{*}{$\circ / \mu$} & r & بلوج \\
\hline & & وضعيت تاهل \\
\hline $7 \mu / 1$ & rvq & متاهل \\
\hline ro/r & rII & بيوه \\
\hline \multirow[t]{2}{*}{$1 / V$} & 10 & 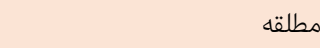 \\
\hline & & تعداد فرزندان \\
\hline$\circ / \mu$ & r & 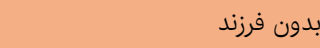 \\
\hline$T / V$ & $\varepsilon_{0}$ & $1-r$ \\
\hline$O V / \mu$ & $\mu \varepsilon \varepsilon$ & $\mu-0$ \\
\hline$\mu_{0} / V$ & $1 \wedge \varepsilon$ & $7-\Lambda$ \\
\hline \multirow[t]{2}{*}{$0 \%$} & $\mu_{0}$ & بيشتر از 9 \\
\hline & & توانايى خواندن و نوشتن \\
\hline$\varepsilon V / V$ & rAT & 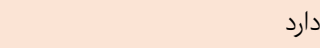 \\
\hline \multirow[t]{2}{*}{$O T / \mu$} & $\mu \varepsilon$ & ن ارد \\
\hline & & وضعيت اشتغال \\
\hline$\mu \%$ & 11 & شاغل فعلى \\
\hline$r / r$ & w & شاغل بعد از بازنشستگىى \\
\hline ro/o & $10 \mathrm{r}$ & بازنشسته \\
\hline$V / r$ & $\varepsilon \mu$ & بيكار \\
\hline \multirow[t]{2}{*}{$7 \pi / 1$} & $\mu \vee \mu$ & خانهدار \\
\hline & & منبع درآمد \\
\hline$\varepsilon 7 / V$ & ru。 & يك منبع درآمد \\
\hline $0 . / 4$ & $\mu_{01}$ & دو منبع درآمد \\
\hline$\mu / \Lambda$ & 19 & بيش از دو منبع درآهد \\
\hline
\end{tabular}

جدول r) توزيع فراوانى مطلق و نسبى وضعيت فعاليت روزمره زندگى (سلامت جسمانى) و بهزيستى روانى در والدين سالمند شهداى شعر شعر تهران (700 نفر)

\begin{tabular}{|c|c|c|}
\hline درصد & 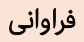 & متغيرها \\
\hline & & فعاليت روزمره زندگى (ADL) \\
\hline $\mathrm{IV} / \mathrm{A}$ & $10 \mathrm{~V}$ & 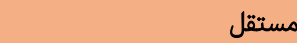 \\
\hline $9 / \mathrm{V}$ & $0 \wedge$ & نيازمند كمك \\
\hline$V r / 0$ & $\varepsilon \mu_{0}$ & 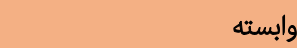 \\
\hline & & ب إهزيستى روانى \\
\hline $0 \% / \Lambda$ & 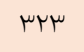 & بززيستى پايين \\
\hline$\varepsilon 7 / r$ & rVV & بهزيستى بالا \\
\hline
\end{tabular}

قرار مىدهد. براى هر آيتم نمرهگذارى از صفر تا ه انجام مى شیود

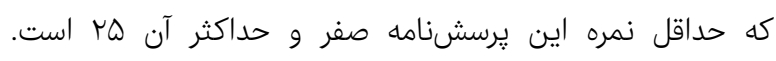

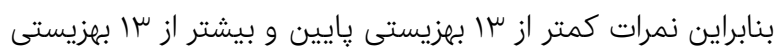

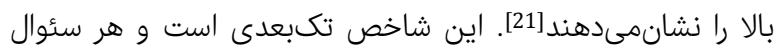

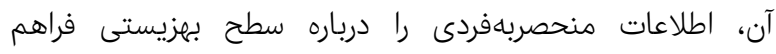

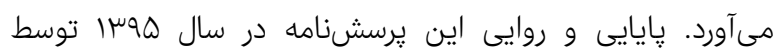

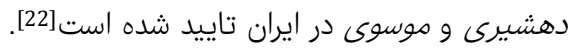

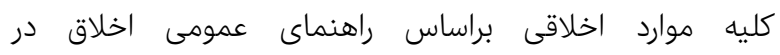

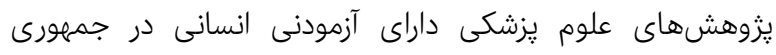

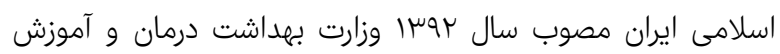

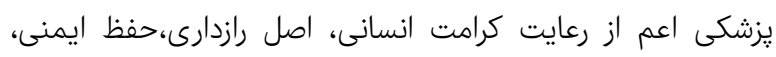

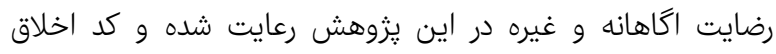

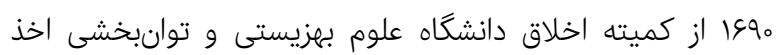

شد.

SPSS 23 تجزيه و تحليل دادههاى مطالعه با استفاده از نرمافزار

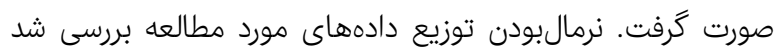

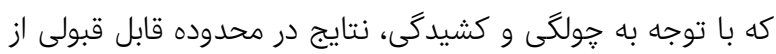

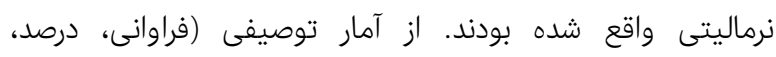

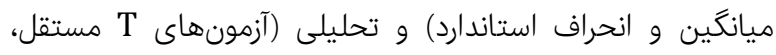

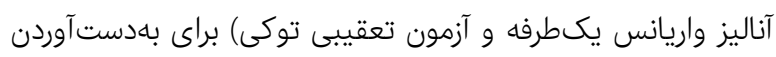

$$
\text { نتايج استفاده شد. }
$$

\section{يافتهها}

ميانكين سنى سالمندان مورد مطالعه بود و اكثريت آنها زن، با قوميت فارني مورد مو متاهل بودند

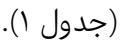

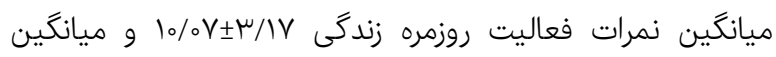

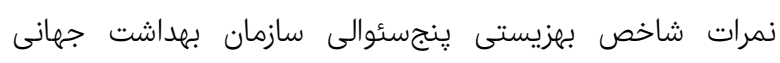

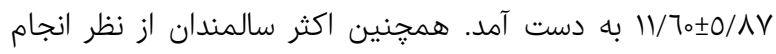

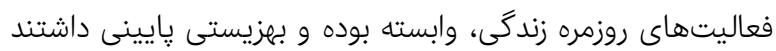

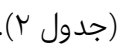

توانايى انجام فعاليت روزمره زندگى بهاعنوان شاخصى از سلامت

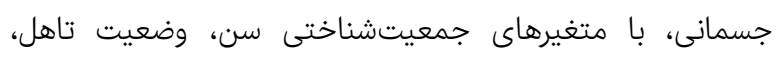
توانايى خواندن و نوشتن و تعداد منابع درآمد ارتباط آمارى

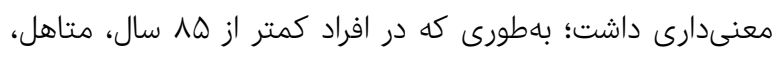

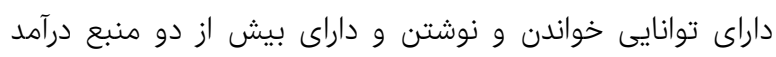

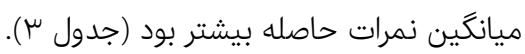

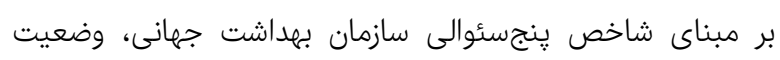

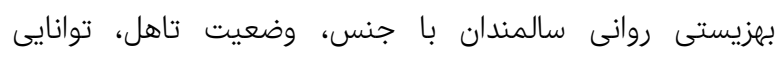
خواندن و نوشتن و تعداد منابع درآمد ارتباط آمارى معنى بدارى

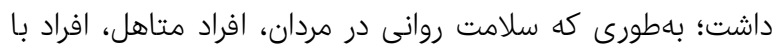

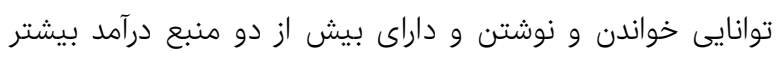

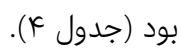


M وضعيت سلامت جسمانى و روانى و عوامل جمعيتشناختى مرتبط با آن در والدين سالمند شهدا...

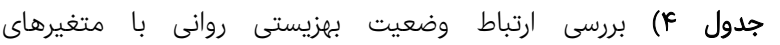

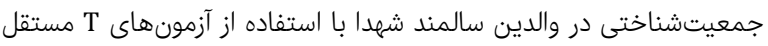

\begin{tabular}{|c|c|c|c|c|c|}
\hline \multirow{2}{*}{ معنىدارى } & \multirow{2}{*}{ درجه آزادى } & \multicolumn{2}{|c|}{ نتايج آزمون آمارى } & \multirow{2}{*}{ نمرات } & \multirow{2}{*}{ دموخيرهاى } \\
\hline & & مقدار F & مقدار t & & \\
\hline \multirow{4}{*}{ 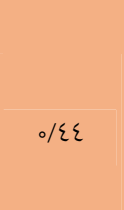 } & & & & & ن (سال) \\
\hline & & & & $1 / 0 \circ \pm 0 / \varepsilon q$ & $7_{0}-V \varepsilon$ \\
\hline & 1 & ०/६1 & - & $V / \varepsilon \mu_{ \pm 0} / \varepsilon V$ & $\vee 0-\wedge \varepsilon$ \\
\hline & & & & $1 / \varepsilon V \pm 0 / 00$ & بالاى 10 \\
\hline \multirow{3}{*}{$\% \mu$} & \multirow{3}{*}{091} & \multirow{3}{*}{ - } & \multirow{3}{*}{$r / 10$} & & نس \\
\hline & & & & 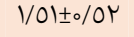 & رد \\
\hline & & & & 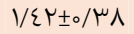 & ن \\
\hline \multirow{6}{*}{$\circ / r_{0}$} & \multirow{6}{*}{ ع و 090} & \multirow{6}{*}{$1 / 00$} & & & فوميت \\
\hline & & & & $1 / 0 \circ \pm 0 / \mu q$ & غارس \\
\hline & & & & $1 / \varepsilon \mid \pm \circ / \varepsilon q$ & نرك \\
\hline & & & - & $1 / \varepsilon \circ \pm 0 / 00$ & كرد \\
\hline & & & & $1 / \varepsilon \wedge \pm 0 / 01$ & ر \\
\hline & & & & $1 / 00 \pm 0 / 01$ & لملوج \\
\hline
\end{tabular}

ب

جدول س) بررسى ارتباط وضعيت فعاليت روزمره زندگى با متغيرهاى

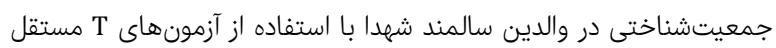
و آناليز واريانس يكىطرفه متغيرهاى

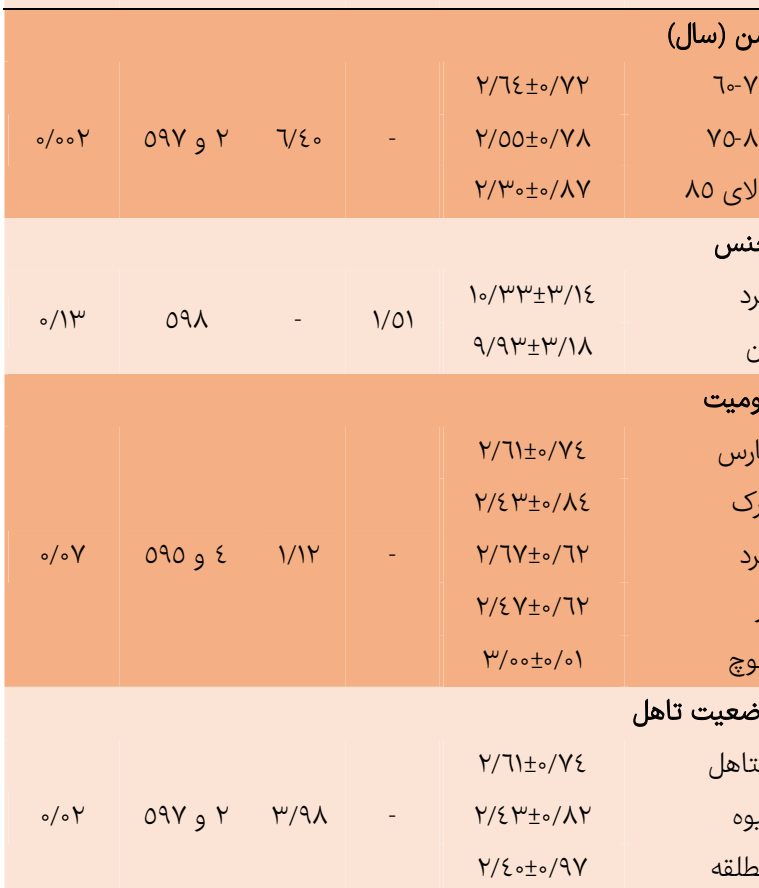

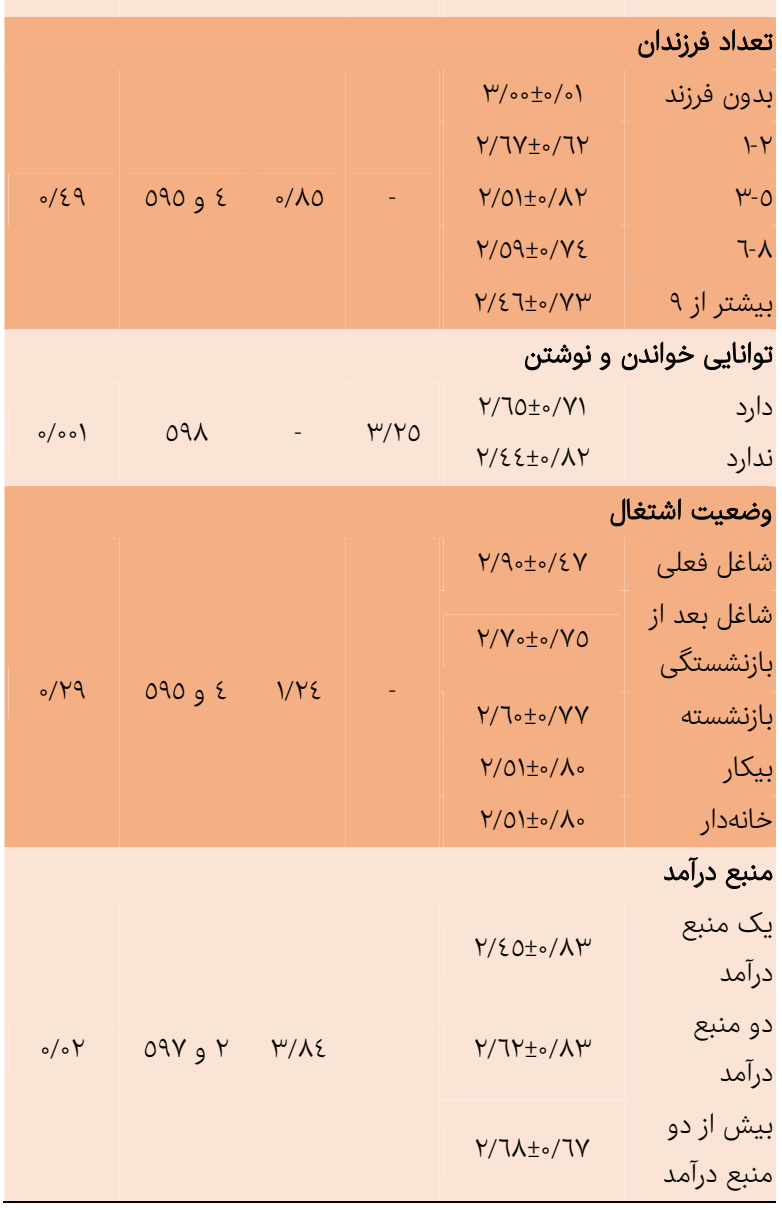


و ايران نسبت به جوامع با وضعيت اقتصادى بالاتر شايد دليل موجهى براى بالاتربودن مشكلات روانى در اين كشورها باشد [34].

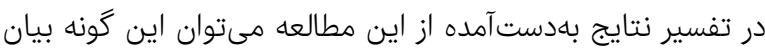

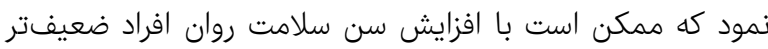

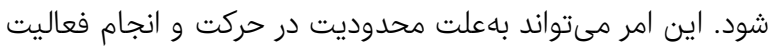

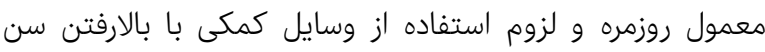
باشد. در اين مطالعه سلامت روانى در مردان، سالمندان متاهل، افراد با دوإن

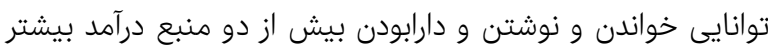
بود. نتايج اين مطالعه با نتايج حاصله از مطالعه نجفى و ودئ همكاران

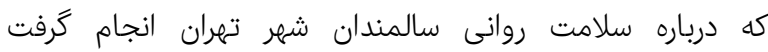
همخوانى داشت. در مطالعه آنها نيز سلامت روانى در مردان و ودران دران

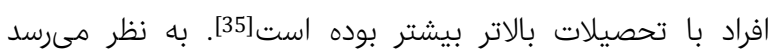

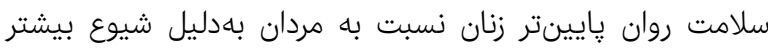

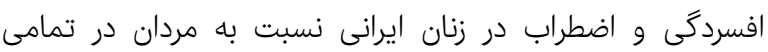
سنين باشد [36]. براساس كزارشات سازمان بهداشت جهانى نيز ميزان افسردگى در برد

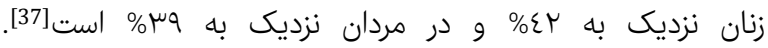

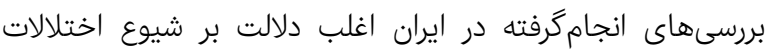

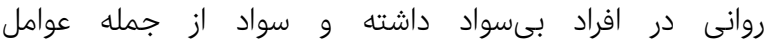

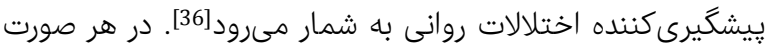

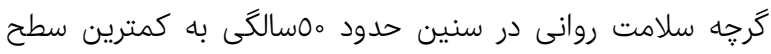

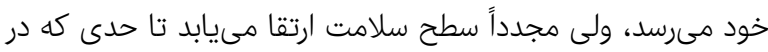

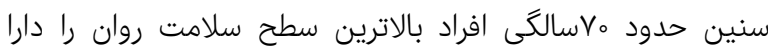

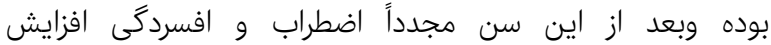

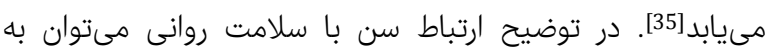
نقش سواد سلامت اشاره نمود و بيان كرد كه احتمالاً افرادى كه

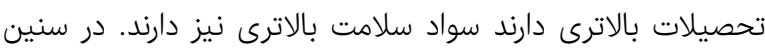

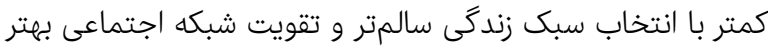

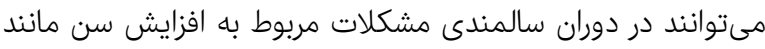

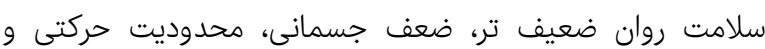

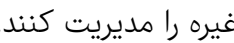

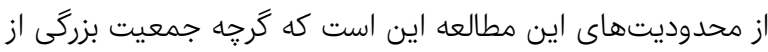
والدين سالمند شهدا در اين مطالعه شركت داشتند، وليكن با توانها

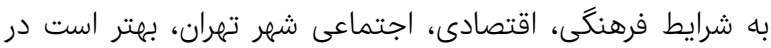

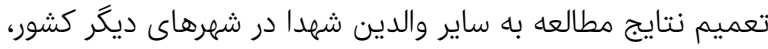

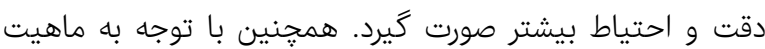
مقطعى مطالعه، از بيان روابط على در مطالعه بايد خوددارى نمود.

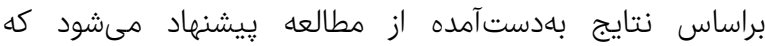

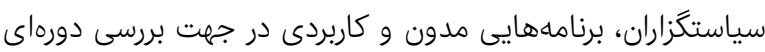

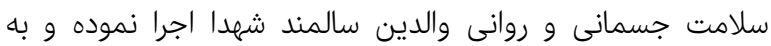

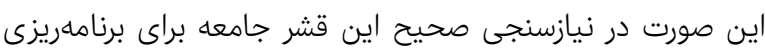

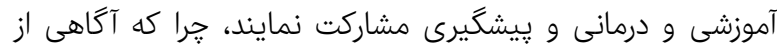

مطالعه حاضر با هدف بررسى وضعيت سلامت جسمانى و روانى و

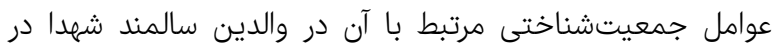

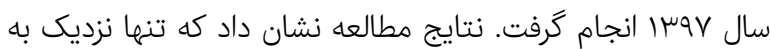

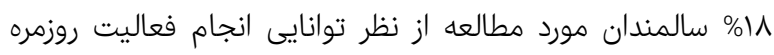

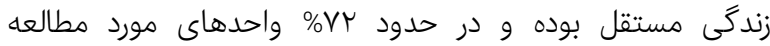
وضعيت توان حركتى خود را وابسته بيان نمودند. اين يافتانه بانها

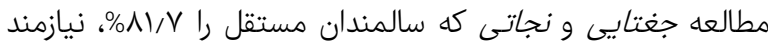

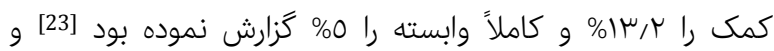

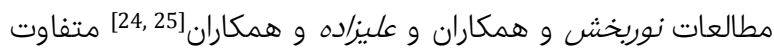

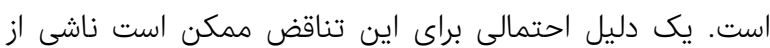
تفاوت در شرايط شغلى سالمندان مورد مطالعه باشد. بناف اصولاً

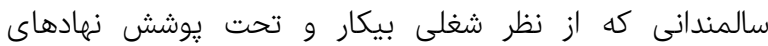

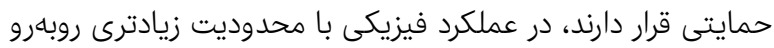

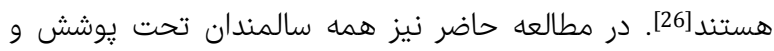

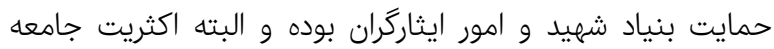

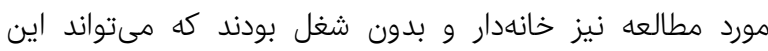

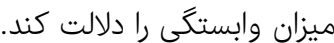

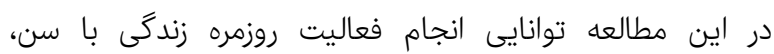

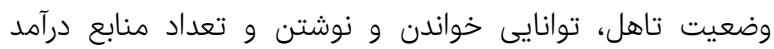
ارتباط داشت. اين نتايج با مطالعه حبيبى و همكاران همخوانى ندانى نداني

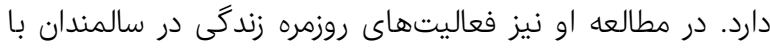

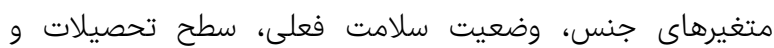

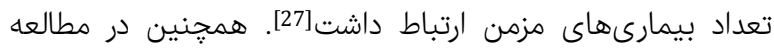

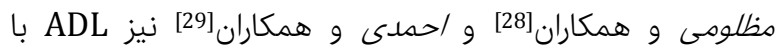
متغيرهاى سن، سطح تحصيلات و تعداد بيمارىهاى مزمن ارنار ارتباط داشت. در مطالعه استورنك و همكاران نيز سالمندان با سطح

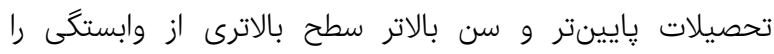

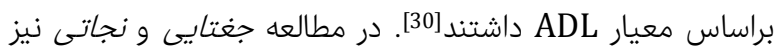

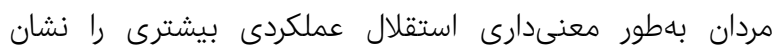

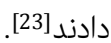

همجنين براساس شاخص پِنجسئوالى سازمان بهداشت جهانى،

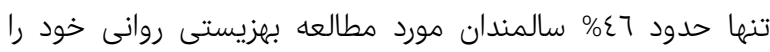
خوب اعلام نمودند كه با مطالعه افضلى و همكاران همخوانى درانى

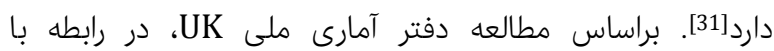

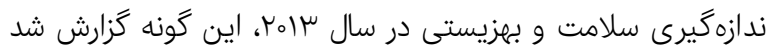

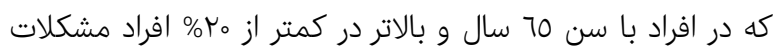

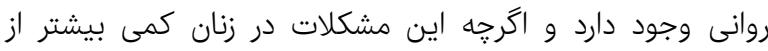

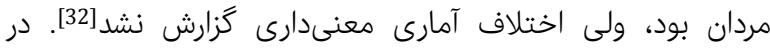

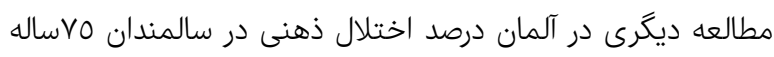

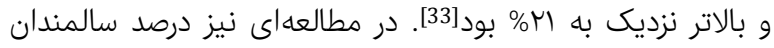

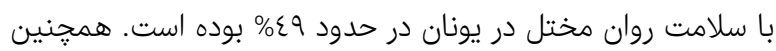
بالاتربودن تنشهاى اجتماعى و اقتصادى در جوامعى نظير يونان 


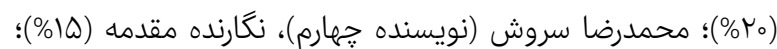

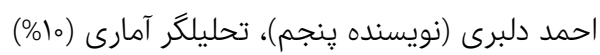

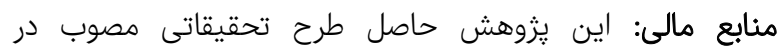

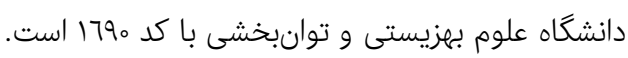

منابع

1- Zarei F, Mohammadi M, Aboozadeh Gatabi K, Ghanbari Moghaddam A. General health and its related factors among elderly in Sabzevar 2016. J Gerontol. 2017;2(2):26-33. [Persian]

2- Borhaninejad V, Momenabadi V, Hossseini SH, Mansoori T, Sadeghi A, Toroski M. Health physical and mental status in the elderly of Kerman. J North Khorasan Univ Med Sci. 2015;6(4):715-25. [Persian]

3- Ahmadi A, Sahaf R, Rashedi V, Akbari Kamrani AA, Shati M, Delbari A. Relationship between oral health and demographic characteristics in retired elderly people in Iran. Salmand: Iran J Aging. 2019;13(4):452-63. [Persian] 4- Sadegh Moghaddam L, Delshad Nobaghi A, Farhadi A, Nazari S, Eshghizadeh M, Choopan Vafa F, et al. Life satisfaction in older adults: role of perceived social support. J Sabzevar Univ Med Sci. 2016;22(6):1043-51. [Persian]

5- Farokhnezhad Afshar P, Asgari P, Shiri M, Bahramnezhad F. A review of the Iran's elderly status according to the census records. Galen Med J. 2016;5(1):1-6.

6- Atadokht A, Zare R, Karamati Topraghloo N. The relationship between social interest and general health among elderly non-resident and resident at geriatric centers of Ardabil city. Iran J Health Educ Health Promot. 2015;3(2):141-9. [Persian]

7- Dziechciaz M, Filip R. Biological psychological and social determinants of old age: bio-psycho-social aspects of human aging. Ann Agric Environ Med. 2014;21(4):835-8.

8- Darvishpoor Kakhki A, Abed saeedi J. Factors related to health-related quality of life (HRQoL) of elderly people in Tehran. Adv Nurs Midwifery. 2013;23(82):8-16. [Persian]

9- Gilhooly M, Hanlon P, Mowat H, Cullen B, Macdonald S, Whyte B. Successful ageing in an area of deprivation: part 1--a qualitative exploration of the role of life experiences in good health in old age. Public health. 2007;121(11):807-13.

10- Aseyedali M, Sadeghi Mahalli N, Noroozi K. A review on adult daycare Centers in the worlds. Salmand: Iran J Aging. 2019;13(4):518-29. [Persian]

11- Eftekhari Z, Nosratinejad F, Sahhaf R, Zanjari N. A Content analysis of the concepts and images of the physical aging primary school textbooks in Iran. Salmand: Iran J Aging. 2018;13(2):154-67. [Persian] 12- Rondón García LM, Ramírez Navarrro JM. The impact of quality of life on the health of older people from a multidimensional perspective. J Aging Res. 2018;2018.

13- Moradpiri H, Heshmati M, Hassanzadeh (Mohammadi) M. An investigation Iraq's strategies against Islamic Republic Iran during the imposed war. Q Compr Holy Defense'. 2017;2(2);83-103. [Persian]

14- Srinivasa Murthy R, Lakshminarayana R. Mental health consequences of war: a brief review of research findings. World Psychiatry. 2006;5(1):25-30.
نيازهاى واقعى و تقاضاهاى سالمندان، نهتنها براى مديران، بلكه

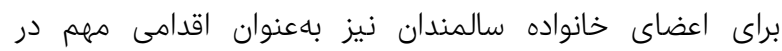

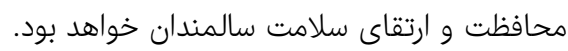
يافتههاى اين مطالعه شواهد قابل توجهى را در زمينه نقش سنام سن،

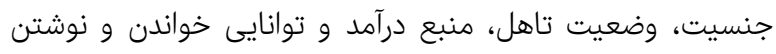

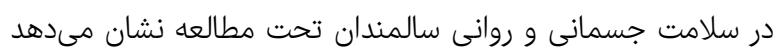

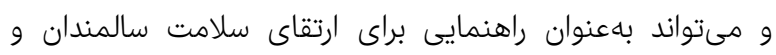

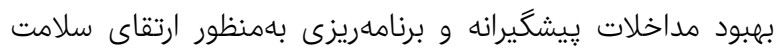

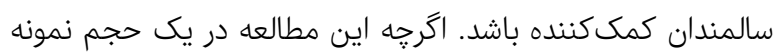

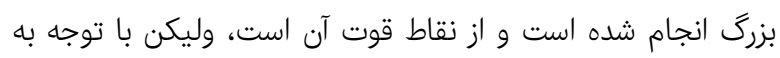

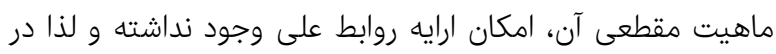
تفسير نتايج بايد دقت بيشترى داشت. براساس نتايت امكان ائ رواين مطالعه

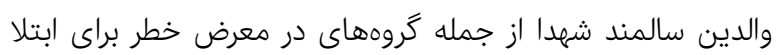
به اختلالات روانى و جسمى هستند و اين موضوع با توجه به إنها

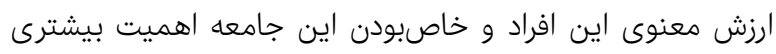

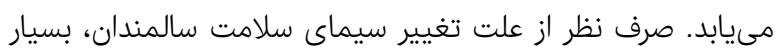

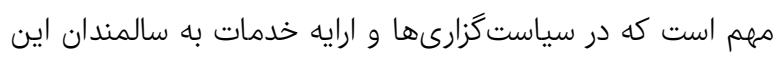

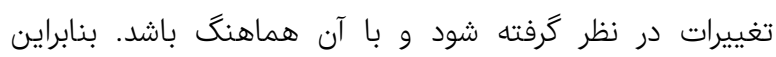

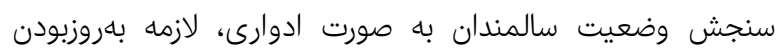
برنامهريزى و ارايه خدمات به سالمندان است.

\section{نتيجه گيرى}

وضعيت سلامت جسمانى و روانى والدين سالمند شهداى شهر

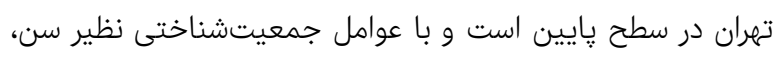
جنسيت، وضعيت تاهل، منبع درآمد و توانايى خواندن و نوشتن رابطه دارد.

تشكر و قدردانى: نويسندكان مراتب قدردانى و سياس خود را از

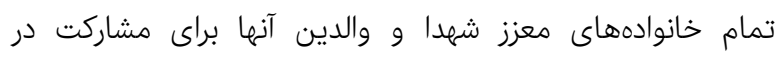

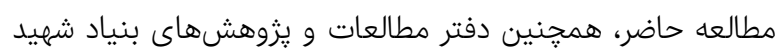

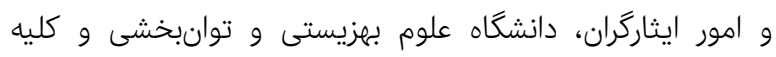
عزيزانى كه كه در اين مطالعه ما را يارى نمودند، اعلام مى داردارند. تاييديه اخلاقى: مطالعه حاضر در كميته اخلاق دانشكاه علوم

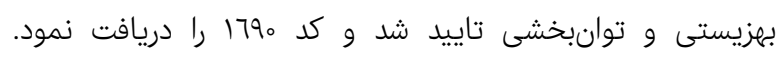
شركت در طرح براى تمامى والدين شهدا كاملاً اختيارى بوده و و

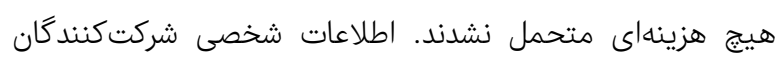

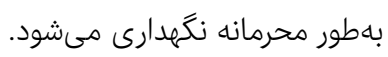
تعارض منافع: هيج گَنه تعارض منافعى از طرف نويسندانَان اعلام نشده است. سهم نويسندكان: راضيه سادات حسينى (نويسنده اول)، نغارنده

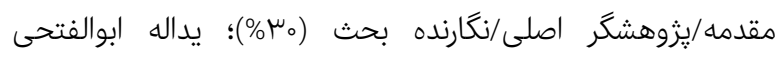

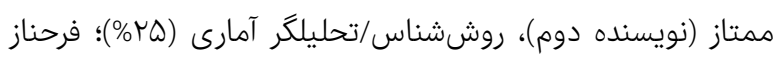

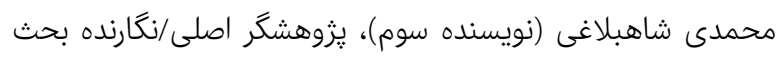


2014;13(6):487-94. [Persian]

27- Habibi A, Nikpour S, Seiedoshohadaei M, Haghani H. Quality of life and status of physical functioning among elderly people in west region of Tehran: a cross-sectional survey. Iran J Nurs. 2008;21(53):29-39. [Persian]

28- Mazloomi Mahmoudabad SS, Soltani T, Morovati MA, Fallahzadeh $\mathrm{H}$. Activities of daily living and prevalence of chronic diseases among elderly people in Yazd. J Toloo-e Behdasht. 2014;13(3):42-53. [Persian]

29- Ahmadi F, Salar A, Faghihzadeh S. Quality of life in Zahedan elderly population. J Hayat. 2004;10(3):61-7. [Persian]

30- Storeng SH, Sund ER, Krokstad S2. Factors associated with basic and instrumental activities of daily living in elderly participants of a population-based survey: the Nord-Trøndelag Health Study, Norway. BMJ Open. 2018;8(3):e018942.

31- Afzali SM, Etemadifar S, Aslani Y, Hasanpour A, Keivani Z. Assessment of psychosomatic health status in elderly population that coverage by Shahrekord Behzisty Center. Avicenna J Nurs Midwifery care. 2008;15(1):3848. [Persian]

32- Beaumont J, Lofts H. Measuring national well-beinghealth, 2013 [Internet]. London: Office for National Statistics; 2013 [cited 2018 June 19]. Available from: https://bit.ly/2XHjZFI.

33- Hoeymans N, Garssen AA, Westert GP, Verhaak PFM. Measuring mental health of the Dutch population: a comparison of the GHQ-12 and the MHI-5. Health Qual Life Outcomes. 2004;2(1):23.

34- Mortazavi SS, Shati M, Eftekhar Ardebili $\mathrm{H}_{\text {, }}$ Mohammad K, Dorali Beni R, Keshteli AH. Comparing the effects of group and home-based physical activity on mental health in the elderly. Int J Prev Med. 2013;4(11):1282-9.

35- Najafi B, Arzaghi M, Fakhrzadeh H, Sharifi F, Shoaei S, Alizadeh $\mathrm{M}$, et al . Mental health status and related factors in aged population: Urban health equity assessment and response tool (Urban- Heart) study in Tehran. Iran J Diabetes Metab. 2013;13(1):62-73. [Persian]

36- Alavi M, Jorjoran Shushtari Z, Noroozi M, Mohammadi Shahboulaghi F. Mental health and related factors in old population in Tehran 2014-2015. J Mazandaran Univ Med Sci. 2018;27(158):112-22. [Persian]

37- Noorbala AA, Bagheri Yazdi SA, Yasamy MT, Mohammad K. Mental health survey of the adult population in Iran. Br J Psychiatry. 2004;184(1):70-3. 15- Aghayousefi A, Sharif N. Personal well-being and stress symptoms in wives of Iranian martyrs, prisoners of wars and disabled veterans. Iran J Psychiatry. 2010;5(1):28-34.

16- Firouzkouhi MR, Zargham Boroujeni A, Nouraei M, Rahnama M, Babaiepour M. The effect of imposed war on Iran's nursing: a historical research. J Milit Med. 2015;17(3):127-36. [Persian]

17- Roshan R, Shakeri R. A study on depression among war martyrs' widows in Tehran using a special depression scale for war martyr's widows. Horizon Med Sci. 2010;16(1):50-9. [Persian]

18- Alizadeh M, Rahimi A, Arshinji M, Sharifi F, Arzaghi $\mathrm{M}$, Fakhrzadeh $\mathrm{H}$. Physical health status and socioeconomic outcomes on elderly in Tehran metropolitan area. Iran J Diabetes Metab. 2013;13(1):29-37. [Persian] 19- Katz S, Ford AB, Moskowitz RW, Jackson BA, Jaffe MW. Studies of illness in the aged. The index of ADL: a standardized measure of biological and psychosocial functions. JAMA. 1963;185(12):914-9.

20- Taheri Tanjani P, Azadbakht M. Psychometric properties of the Persian version of the activities of daily living scale and instrumental activities of daily living scale in elderly. J Mazandaran Univ Med Sci. 2016;25(132):103-12. [Persian]

21- Topp CW, Østergaard SD, Søndergaard S, Bech P. The WHO-5 well-being index: a systematic review of the literature. Psychother Psychosom. 2015;84(3):167-76.

22- Dehshiri Gh, Mousavi SF. An investigation into psychometric properties of Persian version of world health organization Five Well-being Index. J Clin Psychol. 2016;8(2):67-75. [Persian]

23- Joghataei MT, Nejati V. Assessment of health status of elderly people in the city of Kashan. Salmand: Iran J Aging. 2006;1(1):3-10. [Persian]

24- Nourbakhsh SF, Fadayevatan R, Alizadeh Khoei M, Sharifi F. Determining the status of activity of daily living (ADL) and instrumental activity of daily living (IADL) in healthy and cognitive impaired elderlies. Jorjani Biomed J. 2018;5(2):63-77. [Persian]

25- Alizadeh M, Fakhrzadeh H, Sharifi F, Zanjari N, Ghasemi S. Comparative study of physical and mental health status of old people in aged groups of 60-64 and 65-69 years old in Tehran metropolitan area. Iran J Diabetes Metab. 2013;13(1):50-61. [Persian]

26- Bakhtiyari F, Foroughan M, Fakhrzadeh H, Nazari N, Najafi B, Alizadeh M, et al. Validation of the Persian of abbreviated mental test (AMT) in elderly residents of Kahrizak charity foundation. Iran J Diabetes Metab. 